\section{Short Protocols in Molecular Biology, 3rd edition}

Edited by F. Ausubel, R. Brent, R. E. Kingston et al. 1995. ISBN 0-471-13781-2. John Wiley and Sons, Chichester. Pp. 732. $£ 60.00$.

Short Protocols in Molecular Biology is a spiral bound laboratory manual which consists of shortened versions of the most commonly used methods found in the three volume manual Current Protocols in Molecular Biology. The text is in note form with informative illustrations; this style is both concise and systematic. Reagents and solutions are crossreferenced to a core appendix which not only removes most of the clutter from the pages but also creates an extremely useful 70 page section containing recipes for every reagent that comes to mind. The protocols selected for presentation appear to be those which work well and which are the simplest. In many cases, alternative methods are also provided. The text is well referenced.

Despite the fact that this book is a shortened version of another text it remains comprehensive. The 17 chapters consider methods which range from the handling of Escherichia coli to mutagenesis, transfection and protein expression. Between these extremes are very useful sections on, for example, preparation and analysis of both DNA and RNA, screening of DNA libraries and yeast genetics.

The only criticisms are minor. The manual should include more safety information; there are safety warnings concerning various hazards when they are first encountered in the text but these are not always repeated where the hazards occur in other methods. This manual will be 'dipped into' and it would be unfortunate if safety advice were missed. In addition, the very comprehensive nature of the text means that omitted sections on, for example, cloning using the bacterial artificial chromosome, are missed. However, these are small criticisms and the text is an excellent one which is likely to become well used by students and experienced scientists alike. At $£ 60$ the book might seem expensive but this is good value for money for such a comprehensive text.

N. I. LEAVES, J. Z. JORDENS

\section{Infection Control in the Immuno-Compromised Host}

Edited by M. SCHRAPPE and H. SEIFERT. 1995. ISBN 389412-200-5. Blackwell Wissenschafts-Verlag, Berlin. Pp. 156. $£ 29.50$.

This multi-author book is the proceedings of a congress on Infection Control in the Immunocompromised Host held in Cologne in 1993. This congress was linked to the first International Symposium on AIDS in Africa and Europe in 1992 which explains the emphasis on HIV infection, particularly from an African perspective. The authors are mainly German or from other North European countries. The book is relatively short (153 pages) but contains 17 chapters some of which are only a few pages long. Topics are extremely varied, ranging from Vaccination against AIDS; Thoughts and Possible Strategy, and Paediatric Nosocomial Bacteraemia in Rwanda, to Candida Bloodstream Infections: An Epidemiological Overview, and Catheter Infections in Cancer Patients. There is no real theme to the book which is really a collection of individual commentaries. Most are far too short and superficial to make rewarding reading and there are numerous typographical errors.
Although I would applaud the editors in attempting to cover infection control in immunocompromised patients from a worldwide perspective, this book, overall, is very disappointing. The occasional chapter makes interesting reading, for example, the chapter by Phillipe van de Perre on Postnatal Transmission of HIV-1 by Breastfeeding, but I would not recommend the purchase of this book despite the relatively low cost.

\section{J. G. M. HASTINGS}

\section{Bacterial Endotoxins, Progress in Clinical and Biological Research, volume 392}

Edited by J. LEVIN, C. R. ALVING, R. S. MunFord and H. REDL. 1995. ISBN 0-471-12133-9. Wiley-Liss, Inc., New York. Pp. 608. £85.00.

This book is the eighth volume dedicated to bacterial endotoxins in the series entitled Progress in Clinical and Biological Research and constitutes the Proceedings of the Third Conference of the International Endotoxin Society (IES), held in Helsinki in 1994. The continuing expansion of research into bacterial endotoxins from studies on lipopolysaccharide (LPS) genetics and biosynthesis to LPS pathophysiology and therapy for sepsis is reflected in the section headings of this volume: LPS Genes and Biosynthesis; Role of LPS in Pathogenesis: Microbiological, Epidemiological and Environmental Aspects; New Aspects of LPS Chemistry and Structure; Source of LPS: Gut Translocation, Bacteraemia and Antibiotics; Binding and Processing of LPS in Biological Systems; Nitric Oxide Induction by LPS; LPS Signal Transduction; Therapeutic Measures to Eliminate LPS or Interfere With LPS Binding; LPS Antagonists; Tolerance Induction.

Each of the chapters which comprise these sections is written clearly with a background, concise methodology and useful bibliography, making this volume a good up-to-date reference on this important subject. The first chapters are from contributors studying the genetics of the biosynthesis of LPS, which increases our understanding not only of the biosynthesis of these macromolecules but also provides new insights into LPS structure-function relations. Several chapters report on the recent advances that have been made in the area of LPS chemistry, through the use of advanced physico-chemical techniques, and the corresponding advances in relating detailed LPS structural variations to specific disease processes. Many chapters reflect the continued interest in circulating inflammatory mediators including tumour necrosis factor and their clinical significance in the progression of the sepsis syndrome. There is an increasing number of proteins which have been found to bind LPS in the circulation or mediate its effects at the cell surface. Consequently a section of chapters report on CD14 and other LPS binding proteins which greatly modify the biological activity of LPS. These proteins provide a possible therapy for endotoxaemia and several chapters report on the use of recombinant LPS binding proteins in the treatment of gram-negative bacteraemia or sepsis.

This book contains a substantial body of current knowledge on endotoxin which reflects the diverse areas of research on this fascinating molecule. It therefore serves as the best reference on the subject for biomedical researchers and clinicians alike. 